Research Report No. 2/2013

\title{
Pueblos Indígenas en Canadá: Libre Determinación y Derechos a la Tierra (Indigenous Peoples in Canada: Self Determination and Rights to Land)
}

Shin Imai

Osgoode Hall Law School of York University, simai@osgoode.yorku.ca

Follow this and additional works at: http:// digitalcommons.osgoode.yorku.ca/clpe

\section{Recommended Citation}

Imai, Shin, "Pueblos Indígenas en Canadá: Libre Determinación y Derechos a la Tierra (Indigenous Peoples in Canada: Self Determination and Rights to Land)" (2013). Comparative Research in Law \& Political Economy. Research Paper No. $2 / 2013$.

http://digitalcommons.osgoode.yorku.ca/clpe/251 


\section{OSGOODE}

OSGOODE HALL LAW SCHOOL YOR K U N I VERSITY

\section{OSGOODE HALL LAW SCHOOL}

Comparative Research in Law \& Political Economy

RESEARCH PAPER SERIES

Research Paper No. 2/2013

Pueblos Indígenas En Canadá: Libre Determinación Y Derechos a La Tierra (Indigenous Peoples in Canada: Self Determination and Rights to Land)

Shin Imai

\section{Editors:}

Peer Zumbansen (Osgoode Hall Law School, Toronto, Director Comparative Research in Law and Political Economy)

John W. Cioffi (University of California at Riverside)

Leeanne Footman (Osgoode Hall Law School, Toronto, Production Editor)

Comparative Research in Law \& Political Economy 


\section{PUEBLOS INDÍGENAS EN CANADÁ: LIBRE DETERMINACIÓN Y DERECHOS A LA TIERRA}

\section{Shin Imai*}

\section{INTRODUCCIÓN}

A mediados de los años 1980, uno de mis clientes era una comunidad indígena del norte de Canadá. Para llegar a la reserva tuve que hacer un viaje de dos horas en avión desde Toronto hasta una pequeña ciudad en la que pernocté, y abordar a la mañana siguiente otro aparato, esta vez de sólo ocho plazas. La comunidad se encontraba en una apartada isla, sin conexión por carretera o ferrocarril. Cuando el avión aterrizó, sólo pude ver extensos matorrales, interrumpidos únicamente por la rudimentaria pista de aterrizaje y por un polvoriento camino que conducía hasta la aldea. Una línea invisible separaba las tierras públicas pertenecientes a la provincia, en las que se ubicaba la pista, de las tierras públicas federales donde se situaba la reserva.

Los patriarcas de la comunidad manifestaban su preocupación por el creciente consumo de alcohol entre la juventud. Su inquietud se hizo mayor cuando apareció en los bosques el cadáver congelado de un joven que evidentemente había bebido en exceso. Tras escuchar a los ancianos, el jefe y el consejo de la reserva dictaron una disposición que prohibía el consumo de bebidas espirituosas en su territorio. Existía una forma expedita para hacer cumplir la prohibición e impedir la entrada de alcohol: la única manera de llegar al lugar era por avión, así que resultaba fácil registrar el equipaje de los pasajeros tras el aterrizaje.

\footnotetext{
* Profesor en la Facultad de Derecho Osgoode Hall, Universidad de York, Canadá. Parte del presente artículo es basado en un capítulo del libro Indigenous People and the Law: Comparative and Critical Perspectives, eds. Ben Richardson, Shin Imai and Kent McNeil (2009: Hart Publishing). Agradezco a Valerie Crystal y Alejandro Campos por revisar y hacer sugerencias por este artículo, y a Lic. Francisco Gomez por la traducción. Esta obra es una iniciativa del Proyecto Justicia y Responsabilidad Corporativa de Osgoode Hall Law School, Toronto, Canada..
} 
La nación originaria pidió al oficial de policía destinado allí que lo hiciera, y que confiscara todo el licor.

Pero esta idea planteaba un problema legal. Debido a que el avión aterrizaba en tierras pertenecientes a la provincia, sólo era aplicable la legislación provincial. El oficial, que era nombrado por el jefe de policía de la provincia de Ontario, recibió instrucciones de sus superiores de que sólo podía registrar las pertenencias de los pasajeros si había sospechas razonables de que se estaba cometiendo un delito. La posesión de alcohol era lícita en tierras provinciales, así que no había conducta delictiva alguna en bajar con él del avión, y por ello no había motivo para el registro. Esto significaba que el cateo sólo podía realizarse una vez que el individuo pusiera pie en el territorio de la reserva federal, donde la posesión de alcohol era ilícita. Pero existía una dificultad práctica para llevar a cabo esta idea: no existía una cerca que marcara la frontera, y a la policía no le resultaba fácil identificar la línea invisible entre la tierra de la provincia y la tierra federal.

El jefe comunitario, molesto ante tal dificultad, decidió crear una "fuerza de pacificación" integrada por miembros de la propia nación originaria, a fin de registrar a los pasajeros al bajar éstos sus equipajes del avión. Muchos pasajeros cooperaban con los "guardias", pero durante una de esas búsquedas un miembro de la comunidad se opuso al registro. Se suscitó una riña, y se encontró en la maleta del individuo una botella de licor, que fue confiscada y destruida. Ninguna otra acción se tomó contra el sujeto. Éste, sin embargo, se sintió ultrajado y sometió su queja a una clínica de ayuda legal establecida en la población más cercana, a hora y media de viaje en avión. El abogado de la clínica consideró que el registro era ilegal, y que se había producido en tierras provinciales. Ante la ley, los "guardias" no eran más que ciudadanos privados que no tenían derecho alguno a revisar las pertenencias de otros ciudadanos. El abogado ayudó a este miembro de la comunidad a presentar una demanda legal contra los dos "guardias", que fueron entonces procesados por agresión.

Se manejó una gran diversidad de opciones "legales" para tratar este caso. La solución más obvia era que la pista de aterrizaje se reubicase en el territorio de la reserva federal. Sin embargo, la provincia se negó a traspasar la pista al gobierno federal, y éste no tenía en 
mente invertir en la construcción de una nueva en sus propias tierras. Otra propuesta era que la comunidad indígena levantase una gran cerca en torno a la pista de aterrizaje, y que obligase a las personas a pasar por una puerta. Poetas y caricaturistas pronto descubrieron el filón cómico del hecho de construir tal cerca en medio de un territorio inhabitado, con el propósito de resolver el problema que creaba una frontera invisible y sin sentido. Y ocurrió, sin embargo, que algunos abogados del gobierno, con poca comprensión del humor, opinaron que en verdad la cerca era la solución más adecuada. Pero -infortunada o afortunadamente- ni el gobierno federal ni el provincial tenían la intención de pagar esa construcción. Finalmente el asunto nunca se resolvió. Los cargos contra los "guardias" fueron calladamente desestimados, la frontera federal-provincial no se cambió, y sigue en pie el problema de aplicar la prohibición del alcohol.

Todas las comunidades aborígenes en Canadá tienen historias similares, con leyes que resultan apropiadas para las áreas urbanas del sur, pero que se imponen de manera ridícula en el norte remoto. Por ejemplo, Susan Drummond cuenta la anécdota de un joven inuk que fue procesado por un tribunal en una ciudad del sur por un crimen violento. La solución del juez fue sentenciar al joven a regresar a su aislada comunidad norteña. Pero esta comunidad estaba también inquieta en cuanto a la conducta del sujeto, y lo encarceló a su regreso. Sin embargo, el juez sureño ordenó su liberación y amenazó a los miembros de la comunidad con juzgarlos por secuestro. ${ }^{1}$

En las dos historias referidas arriba, el Código Penal funcionó de manera contraproducente para la protección de la comunidad. En la primera, ayudó a proteger a los contrabandistas al hacer muy difícil su detección y procesamiento. En la segunda, el sistema judicial resolvió el caso de un joven problemático en una comunidad sureña haciéndolo regresar a su aislada comunidad del norte. Para proteger a la comunidad del sur, expuso a la norteña a potenciales problemas. Más serio resulta aún, sin embargo, el hecho de que en ambos casos la aplicación del Código Penal despojó de poder a los líderes comunitarios y puso en manos

\footnotetext{
${ }^{1}$ S. Drummond, Incorporating the Familiar: Investigating Legal Sensibilities in Nunavik (Queen's University Press, 1997).
} 
de personas no aborígenes del sur la autoridad y la responsabilidad de tratar asuntos internos de una nación originaria.

Reflejé sobre estas historias al leer el libro Citizens Plus: Aboriginal Peoples and the Canadian State, del politólogo canadiense Alan Cairns. ${ }^{2}$ En esta obra el autor critica a la Real Comisión para los Pueblos Aborígenes, ${ }^{3}$ que recomendó que los gobiernos iniciaran negociaciones con las naciones originarias a fin de incrementar sus bases territoriales y reconocerles facultades decisorias sobre la tierra en sus propias comunidades. Dice Cairns que estos acuerdos hacen énfasis en las relaciones "nación a nación”, en los tratados y en un tercer orden de gobierno para las naciones aborígenes, a expensas de fomentar un "común sentido de pertenencia" mediante instituciones compartidas con otros canadienses. Con respecto a las dos comunidades descritas anteriormente, me pregunto cómo podría decirse que la aplicación del "compartido" Código Penal fomentó su "sentido de pertenencia" a Canadá. Desde el punto de vista de la sociedad dominante, no aborigen, aplicar el mismo Código Penal dentro y fuera de las reservas pudo parecer que fortaleciera la conexión con Canadá; pero desde el punto de vista aborigen, el "sentido de pertenencia" puede no haberse visto como una experiencia particularmente positiva, y probablemente haya contribuido a incrementar su distanciamiento con respecto a Canadá.

La problemática del "sentido de pertenencia" es aún más pertinente cuando se involucra el uso del territorio de una comunidad indígena, porque la tierra está relacionada al entorno político, cultural, social, económico y religioso de dicha comunidad. Un uso del territorio para labores mineras, por ejemplo, puede introducir cambios en los valores éticos de la comunidad, conflictos interfamiliares, una modificación drástica en la organización del trabajo, cambios en la estructura de gobernanza de la comunidad y la destrucción de sitios de importancia espiritual. En este contexto, el "obvio" beneficio que se desprende del trabajo pagado, no compensa la destrucción del "sentido de la comunidad" que éste trae

\footnotetext{
${ }^{2}$ A. Cairns, Citizens Plus: Aboriginal Peoples and the Canadian State (University of British Columbia Press, 2000), pp. 51-52.

${ }^{3}$ Informe de la Royal Commission on Aboriginal Peoples (Supply and Services, Canada, 1996). ('Real Comisión') ). Uno de los señalamientos de Cairns es que la mayoría de los siete comisionados era de procedencia aborigen.
} 
consigo. Es importante señalar que en lo absoluto las reservas con respecto a este tipo de proyectos no es una reacción irracional. Imaginemos, por ejemplo, cómo reaccionarían los ciudadanos de las grandes urbes, si se les presentase una propuesta de convertir sus respectivas ciudades en espacios de producción agrícola, estilo hacienda, y que trabajasen cosechando maíz.

Un problema asociado a lo anterior es el hecho de que los "beneficios" prometidos han sido desproporcionalmente más ventajosos para los dueños de la mina que para los comuneros. Por ejemplo, en mi estudio del caso de una mina canadiense en Guatemala, descubrí que el CEO de la mina, Goldcorp, ganaba US\$23 $000000^{4}$ al año, mientras que el ingreso de los guatemaltecos quienes trabajan para producir esa riqueza sólo asciende a cifras entre US\$2 400 - US\$5 400. ${ }^{5}$ Vale resaltar que los problemas de falta de consulta con las comunidades fueron tan serios, que investigadores del Banco Mundial, institución quien ofreció un préstamo para la mina, sugirieron que la empresa debía suspender la expansión de sus operaciones. En lugar de implementar esta sugerencia, la empresa devolvió el préstamo y se liberó del monitoreo del Banco Mundial. Por otra parte, aun reconociendo que en el corto plazo pueden haberse producido beneficios para las comunidades involucradas en las actividades mineras de Goldcorp, un estudio de Tufts University (EEUU) concluyó que, en términos generales, "los riesgos ambientales superan significativamente a los beneficios económicos de la mina". ${ }^{6}$ Goldcorp, por su parte, ha negado las acusaciones recogidas en este informe. De acuerdo a los datos de Goldcorp, durante un período de 4 años, la contribución de la misma a la comunidad ascendió a un total de \$24000 000. En una respuesta a este alegato de la empresa, los autores del estudio de Tufts University advierten que, durante el período comprendido entre 2006 y 2009, los ingresos que Goldcorp obtuvo gracias a la mina ascendieron a casi US\$1 billón. (US\$ 1,000 millones).

\footnotetext{
${ }^{4}$ The Globe and Mail, April 4, 2007 file:///C:/Users/admin/Desktop/A-Shin/ARTICLES/Glamis/Telfer\%20payday\%20worth\%20\$23million\%20in\%202006.htm

${ }^{5}$ Lyuba Zarsky y Leonardo Stanley, Buscando Oro en el Altiplano de Guatemala: Beneficios económicos y riesgos ambientales de la Mina Marlin (octubre, 2011), p.24

http://ase.tufts.edu/gdae/policy_research/marlinmine_spanish.html\#prensa.

${ }^{6} \mathrm{Ibid}, \mathrm{p} .45$.
} 


\section{LA REALIDAD DE LA LIBRE DETERMINACIÓN}

Existe un creciente reconocimiento internacional del derecho a la libre determinación de los pueblos indígenas. El ejemplo más reciente es la Declaración sobre los Derechos de los Pueblos Indígenas, aprobada por la Asamblea General de Naciones Unidas en 2007, que en su artículo 3 establece: "Los pueblos indígenas tienen derecho a la libre determinación. En virtud de ese derecho determinan libremente su condición política y persiguen libremente su desarrollo económico, social y cultural." ${ }^{7}$

En Canadá, la constitución contiene un reconocimiento de los derechos de los pueblos aborígenes.

s.35 (1) Por este medio se reconocen y afirman los derechos aborígenes existentes y recogidos en los tratados, de los pueblos aborígenes de Canadá.

(2) En esta Ley, "pueblos aborígenes de Canadá" incluye a los pueblos indios, inuit y métis de Canadá.

Casi todas las constituciones en América Latina contienen reconocimiento de los pueblos indígenas.

En parte, el reconocimiento de los pueblos indígenas tuvieron lugar en razón de que los gobiernos no indígenas se percataron de que ya no funcionaban las políticas de asimilación. Los pueblos indígenas habían sobrevivido a las masacres, a las enfermedades traídas por los europeos, a la separación forzosa de sus hijos y a la expulsión en masa de sus territorios, y con todo el "problema indio" no había desaparecido. Por lo contrario, las políticas de asimilación lo habían exacerbado, y los gobiernos enfrentaban la perspectiva de un desastre social y económico, y conflictos permanentes en las comunidades aborígenes.

\footnotetext{
${ }^{7}$ Asamblea General de las Naciones Unidas, 61ra. Sesión, Res. A/RES/61/295, UNGA (13 de septiembre de 2007).
} 
Las áreas de tierra reservadas para uso exclusivo de los pueblos indígenas no son a menudo lo suficientemente extensas como para que brinden el apoyo necesario a las ceremonias tradicionales y las actividades de subsistencia, sin contar los empeños de la vida diaria que van creando la base económica de las comunidades. Los pueblos indígenas necesitan el acceso a, y el control sobre, la tierra y las fuentes de recursos a las que tradicionalmente han accedido para sobrevivir. Reconociendo este hecho, el gobierno federal canadiense se ha comprometido a reconocer la existencia del derecho inherente al autogobierno. En base a la política federal al respecto, se han realizado negociaciones sobre reclamos territoriales y sobre el autogobierno, y desde mediados de los años 1970 se han producido más de una docena de importantes acuerdos, así como innumerables arreglos menores con relación a diferendos sobre la propiedad de las tierras. Las extensiones territoriales contempladas en estos acuerdos van desde las $352238 \mathrm{~km}^{2}$ incluyendo derechos minerales en aproximadamente $35,000 \mathrm{~km}^{2}$ para los inuit del Ártico Oriental hasta solo $7 \mathrm{~km}^{2}$ para los tsawwasen en la Columbia Británica. En el tratado con la nación nisga'a la autoridad indígena es suprema con respecto a algunas materias internas, incluyendo su gobierno y su constitución, su ciudadanía, su cultura y su lengua, sus derechos patrimoniales, el uso de la tierra, la atención a la niñez y la familia, la educación y la propiedad cultural.

Sin embargo, la mayoría de los pueblos indígenas en Canadá se queda sin un acuerdo moderno o demarcación de su territorio tradicional. Para ellos, resulta difícil calcular si a lo largo de los años ha habido o no "progreso" en el tema de las tierras. Ciertamente, en Canadá, los Estados Unidos, Australia y Nueva Zelanda la situación ha mejorado, por cuanto los gobiernos de estas jurisdicciones han manifestado su compromiso por resolver los problemas de la tierra y los recursos. Algunos estudios sobre la propiedad de la tierra demuestran que se han producido avances en cuanto al reconocimiento de las titulaciones de los grupos aborígenes, incluyendo la norma, tanto de derecho internacional como doméstico, de que los gobiernos deben consultar a los pueblos originarios antes de suprimir su acceso a las tierras y los recursos. Por otra parte, este es el ámbito en que los pueblos indígenas reciben la presión más fuerte para aceptar la asimilación. Minería, petróleo y gas, explotación forestal, agricultura, generación hidroeléctrica, urbanización: todas estas actividades se combinan para crear el fundamento de la satisfacción del "bien público", que 
resulta en la transferencia de la propiedad y el manejo de las tierras, de los habitantes indígenas a los gobiernos nacionales. Los enfrentamientos por este motivo continúan en Canadá, Estados Unidos, Australia y Nueva Zelanda, con bloqueos de carreteras y ocupaciones de tierras. $^{8}$

La problemática, entonces, no es sólo de índole legal. Algunas naciones originarias estaban mejor no teniendo ningún derecho reconocido por ley, pero disfrutando en la práctica del control y el uso de sus recursos. La llegada del reconocimiento legal se ha acompañado por la invasión de sus tierras y la expropiación de sus recursos.

La obligación de "consultar y acomodar" a las comunidades indígenas constituye ciertamente un avance con respecto al pasado, cuando no existía tal consulta. Empero, los gobiernos colonizadores se muestran renuentes a reconocer la necesidad del “consentimiento" indígena. Esto significa que por más perfecto que sea el proceso de consulta, los tribunales y los gobiernos no reconocen el derecho de las comunidades a decir “no". Recientemente, en Ontario, Canadá, los kitchenuhmaykoosib inninuwug se vieron envueltos en una disputa bosque adentro, a cientos de millas de distancia de cualquier camino asfaltado, en un área sólo accesible por avión y trineo a motor. ${ }^{9}$ La nación originaria se oponía a la exploración minera en un territorio sobre el cual conservaba aún su derecho a cazar y pescar. Un tribunal le ordenó participar en una "consulta" con la compañía, Platinex, y en el curso de ese proceso la comunidad insistió en que iba a seguir sus propios procedimientos antes de decidir si autorizaba o no la exploración. Al cabo de varios meses el juez decidió que el requisito de la consulta se había cumplimentado, y cuando la nación originaria continuó oponiéndose a la actividad exploratoria, el juez falló que el jefe y la mayoría de los miembros del consejo electo eran culpables de desobediencia de una decisión judicial, y los sentenció a seis meses de prisión. ${ }^{10}$ Era la sentencia más larga de la que se tuviera memoria por desobediencia en el contexto de una acción de

\footnotetext{
${ }^{8}$ Un recuento pormenorizado de la muerte a balazos de un manifestante aborigen por la policía puede encontrarse en: Ontario Government, Report of the Ipperwash Inquiry (Publications Ontario, 2007).

${ }^{9}$ Esta comunidad es la misma que se menciona al inicio de este artículo en la historia sobre el control del alcohol.

${ }^{10}$ Platinex Inc. v. Kitchenuhmaykoosib Inninuwug First Nation, [2008] 2 CNLR 301, 77 WCB (2d) 325 (Ont. Sup. Ct.).
} 
protesta. ${ }^{11}$ No existen precedentes de una similar sentencia a prisión para un alcalde y un consejo municipal de una comunidad no aborigen en una disputa sobre el uso de la tierra. Y para empeorar las cosas, Platinex no era una inocente y bienintencionada compañía minera; aunque había recibido una carta de la nación originaria en la que ésta se oponía a la exploración, en sus declaraciones aseveró que la comunidad había autorizado verbalmente la actividad, ${ }^{12}$ y cuando la comunidad la impidió físicamente, Platinex presentó una demanda por $\$ 10,000$ millones de dólares, lo que era cerca de $\$ 10$ millones por cada hombre, mujer y niño de esta aislada reserva.

A la luz de todos estos conflictos sin resolución, el gobierno pagó CND\$5 000000 a la empresa para retomar la licencia de exploración y suspendió la exploración minera en un predio mayor a $23000 \mathrm{~km}^{2}$, el cual corresponde a los territorios tradicionales. En términos económicos, todo lo anteriormente comentado habla de una situación de suma ineficiencia. El resultado de no permitir la exploración sin el consentimiento, confirma la demanda que la comunidad articuló en primera instancia. En lugar de hacer una consulta apropiada y respetar el proceso comunitario, la empresa y el gobierno emprendieron un proceso probadamente conflictivo, que se extendió por un período mayor a un año, e implicó altos gastos financieros y políticos.

\section{DERECHOS A LA TIERRA}

Debido a que la libre determinación es una elección, puede ejercerse en diferentes maneras. La opción de la "soberanía y el autogobierno" conduce a una mayor autonomía de la comunidad indígena para controlar su propio desarrollo social, económico y político. La opción de la "autoadministración y la autogestión" lleva a un mayor control sobre los asuntos locales y a la prestación de servicios dentro del más amplio marco legislativo del

\footnotetext{
${ }^{11}$ Véase Frontenac Ventures Corp. v. Ardoch Algonquin First Nation, 2008 ONCA 534, 91 OR (3d) 1, párr. 63 (Frontenac). En ese caso, el juez había impuesto al jefe de entonces una sentencia de seis meses y una multa de $\$ 25,000$ dólares por bloquear una mina de uranio en tierras en disputa. La Corte de Apelaciones de Ontario determinó que la sentencia era demasiado fuerte, y la redujo a una multa de $\$ 1,000$ dólares.

${ }^{12}$ Platinex Inc. v. Kitchenuhmaykoosib Inninuwug First Nation, [2006] 4 CNLR 152, 272 DLR (4th) 727 (Ont. Sup. Ct.), párrs. 23-28. La decisión final del juez fue revocada después de que los líderes de la nación originaria habían pasado ya dos meses en la cárcel: Platinex Inc. v Kitchenuhmaykoosib Inninuwug First Nation, 2008 ONCA 533, 91 OR (3d) 18 .
} 
gobierno colonizador. El modelo de la "cogestión y la gestión compartida" institucionaliza la participación indígena en el manejo de las tierras y los recursos. Por último, la "participación en el gobierno público" brinda un medio para influir en las políticas de los gobiernos colonizadores mediante instituciones específicamente indígenas. Dentro de cada una de estas categorías se da una serie de variantes. Estas opciones, por otra parte, no son mutuamente excluyentes, y en algunas jurisdicciones coexisten las cuatro.

Quisiera enfocar mi análisis en un mecanismo utilizado en Canadá para manejar conflictos sobre tierra y el medio ambiente: la cogestión y gestión compartida.

En lugar de generar un conflicto, una forma más refinada que tienen los gobiernos para acceder a las tierras indígenas es mediante los regímenes de cogestión. En un caso típico, se crea una comisión integrada por miembros indígenas y del gobierno. La idea es que este tipo de estructura facilita la colaboración entre las partes. Canadá emplea ampliamente los consejos de cogestión, que constituyen un factor importante en todos los acuerdos sobre reclamaciones de tierras. ${ }^{13}$ La jurisdicción y la composición de cada consejo dependen del acuerdo de que se trate.

Un ejemplo se encuentra en el acuerdo sobre las reclamaciones de tierras en Nunavut. ${ }^{14}$ Se han establecido órganos encargados de la atención a diversos asuntos: la flora y la fauna, la explotación de los recursos y la protección del medio ambiente, para investir formalmente a los inuit con la facultad de hacer recomendaciones a las instancias decisorias gubernamentales. Estos órganos incluyen la Comisión de Planificación de Nunavut, el Consejo de Aguas de Nunavut, el Consejo de Administración de la Flora y la Fauna y el Tribunal de Derechos Territoriales, y están generalmente integrados por un número igual de representantes de la Federación Tunngavik de Nunavut y de los gobiernos federal y territorial. Y ya que los inuit controlan el gobierno del territorio, puede que la mayoría de

\footnotetext{
${ }^{13}$ Para un análisis general, véase el informe de la Royal Commission, nota 3, vol. 2 Pt 2, pp. 665-680. En cuanto a ejemplos en Estados Unidos, ver E. Goodman, "Protecting Habitat for Off-reservation Tribal Hunting and Fishing Rights: Tribal Comanagement as a Reserved Right”, Environmental Law n 30 (2000), p. 279.

${ }^{14}$ Agreement between the Inuit of the Nunavut Settlement Area and Her Majesty the Queen in Right of Canada (Minister of Indian Affairs and Northern Development and Tunngavik, 1993). ("Nunavut Land Claims Agreement").
} 
los miembros de cada órgano sea inuit. Por lo general las decisiones de estos órganos colegiados son sólo sugerencias que se hacen a un ministro del gobierno, quien tomará la decisión final. Sin embargo, el acuerdo hace más difícil ignorar las recomendaciones. A este respecto resulta ilustrativo el proceso de toma de decisiones en el Consejo de Administración de la Flora y la Fauna. Este órgano constituye el principal instrumento regulador de la vida silvestre en el área de asentamiento de los inuit. Su objetivo es crear un sistema de derechos de uso, y establecer prioridades y privilegios que reflejen los métodos tradicionales y actuales de la nación inuit. Cuando el Consejo adopta una decisión, la hace llegar de manera privada al ministro, y si éste decide rechazar la sugerencia debe hacerlo constar por escrito en un término de 30 días y permitir al Consejo reconsiderar su decisión previa. Éste, entonces, reconsiderará el asunto y dará a conocer públicamente su parecer. En ese momento el ministro está en posición nuevamente de aceptar o rechazar la decisión del Consejo. ${ }^{15}$

No obstante, en ciertos casos los consejos de cogestión están investidos de una autoridad más significativa. El Consejo de Evaluación del Impacto Ambiental de Nunavut es la agencia a cargo de esta materia en el área de asentamiento de los inuit. Este consejo examina las posibles afectaciones de los proyectos a la tierra, el agua y el aire, así como a la población inuit, y se basa en el conocimiento tradicional inuit, así como en reconocidos métodos científicos, para valorar y controlar los impactos medioambientales, culturales y socioeconómicos de dichos proyectos. El consejo determina si éstos deben emprenderse, y si así fuere, bajo qué condiciones. Si decide que una determinada propuesta debe ser revisada, solicita al ministro remitir el asunto a un panel gubernamental de evaluación del impacto medioambiental, para su consideración. ${ }^{16}$

En Australia ha habido amplias negociaciones sobre los parques bajo gestión compartida. Los acuerdos particulares al respecto varían, pero todos contienen dos elementos comunes: la participación de los aborígenes en los consejos de administración de los parques, y un contrato de leasing con la correspondiente comunidad indígena. Un acuerdo típico es el del

\footnotetext{
${ }^{15}$ Ibid., art. 5.

${ }^{16}$ Ibíd., art. 12.
} 
Parque Nacional Uluru-Kata Tjuta. A los anangu se les otorgó el título de propiedad sobre el parque, y ellos le arriendan la tierra a la Administración Australiana de Parques por un término de 99 años. El acuerdo de leasing "asegura la preservación de las tradiciones de los anangu mediante la protección de sus sitios sagrados y otras áreas importantes". Los anangu tienen una participación mayoritaria en el consejo de administración, reciben pagos anuales de renta y se benefician de cursos de adiestramiento y de oportunidades de empleo. ${ }^{17}$ Una iniciativa similar existe en Aotearoa/Nueva Zelanda, donde se han realizado negociaciones acerca de tres montañas sagradas. A los maoríes se les ha conferido un papel en el manejo de las montañas. ${ }^{18}$

\section{LA RESPONSABILIDAD DEL PODER JUDICIAL}

Un estado de derecho y el imperio de la ley implican la existencia de un poder judicial independiente y consciente de la responsabilidad de proteger ciudadanos que no tienen poder político o económico, todo ello tomando en cuenta la importancia de un derecho integral. Los pueblos indígenas y las comunidades campesinas no tienen el poder económico de las grandes empresas, ni el poder político de los gobiernos. Para ellos, el poder radica en ejercer el derecho a la libre expresión y la manifestación del disenso a través de protestas en las calles. Por supuesto esta forma de expresión puede parecer incompatible con las leyes de seguridad pública o los intereses económicos de las empresas. ¿En este contexto, cuál es entonces el rol apropiado del poder judicial? Creo que parte de la respuesta se encuentra en un fallo de la corte de apelaciones de Ontario. El fallo en cuestión estuvo relacionado con la protesta anteriormente mencionada la cual trajo como consecuencia sentencias de encarcelación para seis líderes de la comunidad indígena. Al revocar la condena a estos líderes, la corte expresó que el concepto del imperio de la ley involucra más que una aplicación mecánica de la ley y se relaciona con los principios del

17 Véase Australian Department of the Environment, Water, Heritage and the Arts, en www.environment.gov.au/parks/national-parks.html. Para un análisis general, ver D. Craig, "Indigenous Joint Management of National Parks", Australian Indigenous Law Reporter $\mathrm{n}^{\mathrm{o}} 46$ (1999), www.austlii.edu.au/au/journals/AILR/1999/46.html.

${ }^{18}$ J. Ruru, "Indigenous Peoples' Ownership and Management of Mountains: The Aotearoa/New Zealand Experience", Indigenous Law Journal $\mathrm{n}^{\mathrm{0}} 3$ (2004), p. 111. Para una débil modalidad de cogestión sobre otros recursos naturales, véase los planes de gestión de los iwi bajo la Ley de Administración de Recursos, de 1991, www.rmalink.org.nz/view-subprocess.php?id=21. 
respecto a los derechos de grupos étnicos, reconciliación de los intereses de los pueblos indígenas con los intereses de los ciudadanos no indígenas y la aplicación del debido proceso. ${ }^{19}$ La otra parte de la respuesta yace en la observación lógica de que no hay necesidad de un poder judicial si los jueces no hacen más que fortalecer los poderes de los gobiernos y las empresas, dado que los gobiernos y las empresas pueden ejercer sus poderes directamente. Debemos recordar que la "raison d'etre" que se espera del poder judicial en una democracia es justamente para contrapesar los poderes políticos y económicos.

En mi estimación, tomando en cuenta las sentencias de las cortes en Canadá, los EE UU, Australia y Nuevo Zelandia, el poder judicial puede desempeñar un papel importante para mediar los conflictos sobre los derechos de los pueblos indígenas, sus tierras y el medio ambiente. Hay cuatro medios o puntos de intervención disponibles a las cortes.

\section{Garantizar un proceso justo y equitativo}

Un proceso de consulta, negociación, diálogo, mediación o discusión es imprescindible para resolver diferencias en intereses y derechos fundamentales. Para promover resultados justos es necesario que la corte asegure que exista participación de buena fe y que exista un equilibrio en el acceso a los recursos necesarios para hacer decisiones informadas. Lo último implica, por ejemplo, que la comunidad indígena o campesina tenga acceso a la representación legal y a expertos independientes.

Resulta evidente que meros "talleres informativos" no cumplen con esta obligación. La diferencia entre un taller informativo y una consulta se ha señalado por James Anaya, Relator Especial de Naciones Unidas sobre la Situación de los Derechos y Libertades Fundamentales de los Pueblos Indígenas:

Se hace más hincapié en que las consultas sean negociaciones en procura de acuerdos mutuamente aceptables y se celebren antes de la adopción de las decisiones sobre las medidas propuestas, y no consultas con el carácter de mecanismos para proporcionar a los pueblos indígenas información sobre decisiones

\footnotetext{
${ }^{19}$ Frontenac, nota 9, párrs. 41-42.
} 
que ya se han adoptado o están en proceso de adoptarse, sin permitirles influir verdaderamente en el proceso de adopción de decisiones.$^{20}$

En Canadá es el gobierno, y no la compañía minera, el que tiene el deber de asegurar que se produzca un apropiado nivel de consulta y acuerdo, lo que no puede lograrse mediante los talleres informativos, que omiten incluir la posibilidad de tener en cuenta los intereses indígenas o arribar a un acuerdo. La Corte Federal de Canadá señaló lo siguiente en el caso Mikisew Cree First Nation v Canada (Minister of Canadian Heritage):

Carece de sentido la consulta que excluya desde el inicio cualquier forma de acuerdo. El proceso que se contempla no es simplemente el de dar a los mikisew una oportunidad para desahogarse antes de que el ministro proceda a hacer lo que desde antes ya tenía planeado. ${ }^{21}$

Las circunstancias actuales van a dictar el tipo del proceso y no es necesario que éstos sean muy complejos. La Corte Suprema en Canadá falló en el caso Haida Nation v. British Columbia $^{22}$ que debe existir una escala o banda fluctuante de complejidad. Por ejemplo, en casos de impactos no serios, informes y discusiones pueden ser apropiados. Por otra parte, en casos en los cuales los impactos sean de mayor seriedad, debe haber un proceso elaborado que incorpore abogados y expertos independientes.

Un papel importante para el juez es indagar si los representantes de la comunidad tienen el apoyo de sus miembros. Globalmente hay casos en los cuales las empresas o los gobiernos hacen acuerdos con "lideres" corruptos. Aunque parece conveniente para el gobierno o la empresa en el corto plazo, como he comentado con anterioridad en el largo plazo, la ausencia de consentimiento por parte de la mayoría de la comunidad, suele convertirse en una fuente de conflicto. Por otra parte, desde el punto de vista del imperio de la ley, ninguna corte puede sancionar un proceso corrupto.

\footnotetext{
${ }^{20}$ Consejo de Derechos Humanos de la ONU, Informe del Relator Especial sobre la Situación de los Derechos Humanos y las Libertades Fundamentales de los Pueblos Indígenas, James Anaya, Doc. ONU A/HRC/12/34, 15 de julio de 2009, párrafo 46; en internet: http://unsr.jamesanaya.org/docs/annual/2009_hrc_annual_report_sp.pdf.

${ }^{21}$ Mikisew Cree First Nation v Canada (Minister of Canadian Heritage, 2005 SCC 69, 3 SCR 388, párr. 54.

${ }^{22}$ Haida Nation v. British Columbia (Minister of Forests), 2004 SCC 73, [2004] 3 SCR 511.
} 


\section{Suspender actividades de exploración o explotación hasta el fin del proceso}

En muchos casos, los conflictos surgen rápido, y no hay tiempo para una sentencia final por una corte de apelación o un tribunal constitucional. Durante este periodo de incertidumbre con relación a los derechos vigentes, ¿cual es la responsabilidad del poder judicial?

El principio del statu quo dicta que pendiente un resultado final, la corte no debe cambiar lo que ya existe. En el pasado, en los casos de conflicto con pueblos indígenas, la mayor parte de los jueces canadienses consideraba que el statu quo se determinaba en referencia a las leyes vigentes o los intereses económicos de las empresas no indígenas. Este tipo de razonamiento trajo como consecuencia que no hubiera incentivos para que el gobierno o las empresas trataran de alcanzar un acuerdo con las comunidades. Mientras "el dialogo" se extendía sin una conclusión, la empresa podía seguir con su explotación. El resultado es que los recursos pueden agotarse o la tierra destruida, antes de que la corte emitiera una sentencia final. Cuando exista la posibilidad de que los intereses de los pueblos indígenas resulten afectados significativamente, la consulta no tendrá sentido si se realiza cuando ya el proyecto está en ejecución. En el caso Saramaka la Corte Interamericana de Derechos Humanos ordenó al Estado de Surinam "delimitar, demarcar y otorgar título colectivo del territorio de los miembros del pueblo saramaka", y que hasta tanto no hiciera eso, el Estado "debe abstenerse de realizar actos [como otorgar concesiones] que podrían [...] afectar la existencia, valor, uso o goce del territorio al cual tienen derecho los integrantes del pueblo Saramaka, a menos que el Estado obtenga el consentimiento previo, libre e informado de dicho pueblo". ${ }^{23}$

En el marco del sistema legal de Canadá no resulta infrecuente que una corte suspenda o retrase un proyecto para asegurar que se cumplan los requerimientos de consulta y que se tengan en cuenta los intereses aborígenes. En el caso de Haida Nation v. British Columbia ${ }^{24}$ falló que debe haber consultas antes de la propuesta de exploración o explotación y las

\footnotetext{
${ }^{23}$ Corte Interamericana de Derechos Humanos, Caso del Pueblo Saramaka vs. Surinam, Sentencia del 28 de noviembre de 2007 (Excepciones Preliminares, Fondo, Reparaciones y Costas), p.65. [Saramaka].

${ }^{24}$ Supra, nota 22.
} 
cortes pueden suspender las actividades de las empresas hasta el fin del proceso de consulta o negociación. En el caso Yellowknives Dene First Nation v. Canada (Attorney General), la Corte Federal anuló un permiso que permitía a una compañía realizar actividades extractivas en tierras que incluían territorios tradicionales de las Naciones originarias. La Corte falló que la compañía había omitido consultar a las Naciones Originarias, y que el gobierno federal había descuidado asegurar que la consulta se realizase. ${ }^{25}$ En otras palabras, las cortes consideran que la determinación del statu quo debe incluir el interés indígena en la preservación de su territorio y el medio ambiente.

Semejante a la escala de complejidad para negociaciones, hay una escala en la toma de decisiones en el caso de suspensión. En casos con impactos irreversibles o muy serios, una suspensión es justificada. En casos con impactos menos serios puede haber una suspensión por un plazo limitado para dejar a las partes presentar información a la corte.

\section{Evaluar los resultados de la consulta o la negociación}

La responsabilidad del gobierno con relación a la explotación de tierra indígena no se resume a la mera consulta, sino también a la de tomar en cuenta las necesidades de la acomodar. Sin esta última obligación, los procesos de consulta, negociación etcétera corren el riesgo de caer en un formalismo vacío, sin contenido. Para evitarlo, las cortes deben indagar en las opciones sugeridas, las posibilidades consideras y las decisiones tomadas. En casos en los cuales no se llega a un acuerdo, la corte debe imponer una resolución. Las cortes, en algunos casos, deciden que, después del fin del proceso, los propósitos del gobierno o la empresa son justificados. En otros casos, hay sentencias que demandan cambios en las propuestas de los defensores del proyecto.

Lo que es importante es que el poder judicial se involucre no meramente en el proceso de resolución del conflicto, sino también en la evaluación de los resultados del proceso.

\section{En casos apropiados, prohibir la actividad o terminar el proyecto}

\footnotetext{
${ }^{25}$ Yellowknives Dene First Nation v. Canada (Attorney General), 2010 FC 1139, [2011] 1 CNLR 385
} 
Un tema de la prioridad en relación del acceso a las tierras de comunidades indígenas y campesinas es el del "veto". ¿Quién tiene el derecho a decidir si va a haber explotación o no? Si no hay el derecho del "veto", implica que no existe el derecho del consentimiento?

Por supuesto, los gobiernos y las empresas niegan que exista un derecho general de veto y promueven el mero derecho de la consulta. Hasta el momento no hay un consenso entre los expertos, y quizás nunca va a haber un consenso sobre un derecho generalizado para el veto. A pesar de esto, es claro que habrá casos específicos en donde el consentimiento es necesario. En el caso de Delgamuukw v. British Columbia, la Corte Suprema de Canadá falló que el consentimiento es necesario si el proyecto de explotación trae como consecuencia la destrucción del medio ambiente, de una forma que afecta el desenvolvimiento de las actividades tradicionales de caza y pesca. ${ }^{26}$

James Anaya, el Relator Especial sobre los derechos humanos y libertades fundamentales de los indígenas de la ONU explicó la relación entre el "veto" y el consentimiento:

Cuando el Relator Especial afirma que los pueblos indígenas no gozan de un derecho al veto en el contexto de los procesos de consulta, se refiere a aquel planteamiento, a su juicio insostenible, de un poder de decisión absoluto de vedar o impedir unilateralmente, con base en cualquiera justificación o sin ninguna, toda propuesta o decisión hecha por el Estado que les pueda afectar. ${ }^{27}$

No obstante, en algunos casos, el consentimiento de la comunidad es necesario para la exploración o la explotación:

... en aquellos casos en que el impacto de una propuesta o iniciativa sobre el bienestar o derechos de un pueblo indígena es significativo, el consentimiento de la parte indígena, por medio de un acuerdo, no solamente es el objetivo de la consulta ${ }_{28}$ ero también es una precondición exigible para la ejecución de la medida propuesta.

\footnotetext{
${ }^{26}$ Delgamuukw v. British Columbia, [1997] 3 SCR 1010, 153 DLR (4th) 193, párr. 168.

${ }^{27}$ Declaración pública del Relator Especial sobre los derechos humanos y libertades fundamentales de los indígenas, James Anaya, sobre la "Ley del derecho a la consulta previa a los pueblos indígenas u originarios reconocido en el Convenio No. 169 de la Organización Internacional de Trabajo" aprobada por el Congreso de la República del Perú, 7 de julio de 2010, punto 1.

${ }^{28}$ Ibid, punto 4.
} 
La Corte Interamericana ha señalado que el estado es responsable de asegurar que, previamente a la toma de una decisión, los miembros de la comunidad tengan conocimiento de los posibles riesgos, incluyendo los medioambientales y de salud, que el proyecto minero pudiera implicar. ${ }^{29}$ Las provisiones de la Declaración sobre los Derechos de los Pueblos Indígenas, aprobada por la Asamblea General de Naciones Unidas en 2007, reflejan también estos principios. ${ }^{30}$

Por último, ya sea que los pueblos indígenas tengan o no el derecho del veto, no hay duda que las cortes tienen el derecho en casos apropiados de parar y terminar proyectos de explotación. En lo particular, las cortes de todos los países en mi estudio han seguido esta práctica.

\section{CONCLUSION}

Hasta el momento la historia nos ha enseñado tres cosas. Primero, que los pueblos indígenas no van a desaparecer. Segundo, que las políticas de asimilación han resultado un fracaso total. Y tercero, que la explotación de los recursos naturales involucra una relación intima con el tema de la libre determinación y derecho a la tierra de las comunidades indígenas. En ese sentido, debe tenerse en cuenta el importante rol que el poder judicial debe desempeñar en la promoción de soluciones justas, viables y de largo plazo.

\footnotetext{
${ }^{29}$ Corte Interamericana de Derechos Humanos, Caso del Pueblo Saramaka (Suriname), 2007, Serie C, $\mathrm{n}^{\circ} .172$, párr. 134.

${ }^{30}$ 2007, UNGAOR, 62 Ses., Annex, Agenda Ítem 68, UN Doc. A/61/L.67, p. 1.

La Declaración establece que la consulta para obtener el consentimiento libre e informado de los pueblos indígenas, antes de llevar a cabo cualquier proyecto afectando su tierra, particularmente en conexión con los recursos minerales, es el estándar mínimo para la sobrevivencia, dignidad y bienestar de los pueblos indígenas: ibíd., arts. 32(2), 43.
} 


\section{Bibliografía}

Australian Government

2012

Australian Department of the Environment, Water, Heritage and the Arts, www.environment.gov.au/parks/national-parks.html.

Asamblea General de las Naciones Unidas

2007

61ra. Sesión, Res. A/RES/61/295, UNGA (13 de septiembre).

Cairns, A.

2000

Citizens Plus: Aboriginal Peoples and the Canadian State (University of British Columbia Press).

Comisión Interamericana de Derechos Humanos

2004 Comunidades Indignas Maya del Distrito Toledo (Belize), Informe $\mathrm{n}^{\circ} 40$, Caso 12.053 .

Comisión Interamericana de Derechos Humanos

2002 Mary y Carrie Dann (Estados Unidos), Informe nº 75, Caso 11.140.

Corte Interamericana de Derechos Humanos

2007 Caso del Pueblo Saramaka (Suriname), 2007, Serie C, n $^{0} 172$.

Craig, D.

1999 "Indigenous Joint Management of National Parks", Australian Indigenous Law

Reporter $n^{\circ}$ 46, www.austlii.edu.au/au/journals/AILR/1999/46.html.

Drummond, S.

1997

Incorporating the Familiar: Investigating Legal Sensibilities in Nunavik (Queen's University Press).

Goodman, E.

2000

"Protecting Habitat for Off-reservation Tribal Hunting and Fishing Rights: Tribal

Comanagement as a Reserved Right", en Environmental Law n 30.

Kamphuis, Charis

2012

"Derecho y la Convergencia del Poder Público y el Poder Empresarial: La

Desposesión Campesina y La Coerción Privatizada en el Perú”, Revista

Latinoamericana de Derecho Social n ${ }^{\circ}$ 15: Universidad Nacional Autónoma de

México Instituto de Investigaciones Jurídicas, http://ssrn.com/abstract=1879947.

Minister of Indian Affairs and Northern Development and Tunngavik

1993

Agreement between the Inuit of the Nunavut Settlement Area and Her Majesty the Queen in Right of Canada. 
Ontario Government

2007 Report of the Ipperwash Inquiry (Publications Ontario).

Real Comisión para los Pueblos Aborígenes

1996 Informe de la Real Comisión para los Pueblos Aborígenes (Supply and Services, Canada).

Resource Management Act

1991 Iwi Management Plans, www.rmalink.org.nz/view-subprocess.php?id=21.

Ruru, J.

2004 “Indigenous Peoples’ Ownership and Management of Mountains: The

Aotearoa/New Zealand Experience”, Indigenous Law Journal nº 3.

UNGAOR

200762 Ses., Annex, Agenda Ítem 68, UN Doc. A/61/L.67.

Zarsky, Lyuba y Stanley, Leonardo

2011 Buscando Oro en el Altiplano de Guatemala: Beneficios económicos y riesgos ambientales de la Mina Marlin (octubre),

http://ase.tufts.edu/gdae/policy_research/marlinmine_spanish.html\#prensa. 